\title{
COST AND EFFICACY OF SURGICAL LIGATION VERSUS TRANSCATHETER COIL OCCLUSION OF PATENT DUCTUS ARTERIOSUS
}

John A. Hawkins, MD

L. LuAnn Minich, MD

Lloyd Y. Tani, MD

Jane E. Sturtevant, BSN

Garth S. Orsmond, MD

Edwin C. McGough, MD
Objective: The purpose of this study was to compare cost and efficacy of surgical closure of patent ductus arteriosus using new critical pathway methods with outpatient transcatheter coil occlusion of patent ductus arteriosus. Methods: Surgical techniques included a transaxillary, muscle-sparing thoracotomy, triple ligation of the patent ductus arteriosus, no chest tube, and discharge from the hospital within 24 hours. Transcatheter coil occlusion of patent ductus arteriosus was done as an outpatient procedure. Costs were compared with inclusion of all hospital and professional charges. Results: From July 1994 until March 1996, 20 patients underwent coil occlusion of patent ductus arteriosus and 20 patients underwent surgical closure of patent ductus arteriosus. Duration of hospitalization was significantly less for the patients receiving coil occlusion (11 \pm 6 hours) as compared with that for the patients having surgical ligation ( $28 \pm 7$ hours, $p<0.05$ ). Total charges were similar for surgical ligation $(\$ 7101 \pm \$ 408)$ as compared with those for coil occlusion (\$7104 $\pm \$ 886, p>0.05$ ). Morbidity in coil occlusion included inability to occlude the patent ductus arteriosus in two patients $(2 / 20,10 \%)$ and residual patency in two patients $(2 / 18,11 \%)$. Morbidity in the surgical group included nausea and vomiting necessitating hospitalization for more than 36 hours in one patient $(1 / 20,5 \%)$, transient left recurrent laryngeal nerve palsy in one $(1 / 20,5 \%)$, and pneumothorax in two patients $(2 / 20,10 \%)$. There were no instances of residual patency in the surgical group. Conclusions: Transaxillary thoracotomy without tube thoracostomy and with critical pathway methods allows safe and effective ligation of a patent ductus arteriosus with early hospital discharge. This surgical method has similar cost, higher efficacy rate, and applicability in all patients as compared with newer transcatheter coil occlusion techniques for closure of a patent ductus arteriosus. (J Thorac Cardiovasc Surg 1996;112:1634-9)
T reatment of patent ductus arteriosus (PDA) has traditionally been surgical with ligation or division of the ductus arteriosus through a thoracotomy

From the Division of Cardiothoracic Surgery and Pediatric Cardiology, Departments of Surgery and Pediatrics, Primary Children's Medical Center and the University of Utah, Salt Lake City, Utah.

Read at the Seventy-sixth Annual Meeting of The American Association for Thoracic Surgery, San Diego, Calif, April 28-May 1, 1996.

Received for publication May 6, 1996; revisions requested June 20, 1996; revisions received July 22, 1996; accepted for publication July 24, 1996.

Address for reprints: John A. Hawkins, MD, Cardiothoracic Surgery, Primary Children's Medical Center, 100 North Medical Dr., Salt Lake City, UT 84113.

Copyright (C 1996 by Mosby-Year Book, Inc.

$0022-5223 / 96 \$ 5.00+0 \quad \mathbf{1 2 / 6 / 7 6 8 2 5}$ incision. ${ }^{1,2}$ Newer transcatheter therapies have emerged in the past several years with the introduction of the Rashkind occluder device ${ }^{3}$ and occlusion with the use of Gianturco coils. ${ }^{4}$ Recent surgical techniques have also been developed to ligate a PDA with use of "minimally invasive" thoracoscopic methods. ${ }^{5}$ Controversy exists concerning the cost, efficacy, and complication rates for surgical closure as compared with transcatheter closure of a ductus arteriosus. One large multicenter study has demonstrated surgical ligation of a PDA to be more cost effective and to have a higher efficacy rate than transcatheter ductal occlusion with the Rashkind occluder device. ${ }^{3}$ Similar comparisons have demonstrated that transcatheter coil occlusion is more cost effective and just as efficacious as surgical ligation. $^{6,7}$

Current trends in critical pathway methods in 
Table I. Results of transcatheter coil occlusion and surgical ligation in 40 patients

\begin{tabular}{lcc}
\hline & Coil occlusion & Surgical ligation \\
\hline Patients $(n)$ & 20 & 20 \\
Age & $4.1 \pm 4.9 \mathrm{yr}($ range $6 \mathrm{mo}-15 \mathrm{yr})$ & $3 \pm 3.9 \mathrm{yr}(\mathrm{range} 4 \mathrm{mo}-10 \mathrm{yr})$ \\
Weight $(\mathrm{kg})$ & $18 \pm 16$ & $12 \pm 7$ \\
Procedure length (min) & $101 \pm 42$ & $46 \pm 6^{*}$ \\
Duration of hospitalization $(\mathrm{hr})$ & $11 \pm 6$ & $27 \pm 6^{*}$ \\
Total charges $(\$)$ & $7105 \pm 886$ & $7101 \pm 407$ \\
Color Doppler patency $(n)$ & $2(2 / 18,11 \%)$ & $0(0 / 20,0 \%)$ \\
\hline
\end{tabular}

${ }^{*} p<0.05$.

operations for congenital heart disease ${ }^{8}$ have led us to use techniques that allow operation for PDA with early hospital discharge and minimal morbidity. This study compares current costs and efficacy of surgical ligation with those of newer transcatheter coil occlusion techniques for the treatment of PDA.

\section{Material and methods}

Patient population. Between July 1994 and March 1996, nonneonatal patients with isolated PDA were given the option of closure of the PDA by thoracotomy and surgical ligation or by transcatheter coil occlusion. Patients were not randomized to one treatment or the other, but rather were selected for coil occlusion on the basis of patient preference and the presence of a ductus arteriosus that appeared to be relatively small $(\leq 5 \mathrm{~mm}$ ) on preoperative echocardiography and color Doppler evaluation. Patients were referred for operative closure on the basis of patient preference for operation or the presence of a ductus arteriosus thought to be too large for coil occlusion. July 1994 coincided with the time we began to use critical pathway methods and axillary thoracotomy to reduce cost and resource utilization for surgical patients with PDA. This also coincided with the period when transcatheter coil occlusion techniques were introduced at our institution to close small PDAs.

All patients underwent a routine preprocedure evaluation with electrocardiography, chest roentgenography, and echocardiography. Surgical patients were admitted to the hospital the day of operation and duration of hospitalization was determined from the time of operation to the time of hospital discharge. Patients who underwent transcatheter coil occlusion were not admitted to the hospital and underwent the procedure on an outpatient basis. ${ }^{9}$ Duration of hospitalization for coil occlusion was defined as the time from the coil occlusion procedure to discharge home. All patients underwent late evaluation for the presence of residual patency with the use of color-flow Doppler echocardiography and successful occlusion was defined as no evidence of any residual flow.

Techniques. Surgical patients were admitted to the hospital the day of operation and underwent operation with use of general anesthesia. Operative exposure was attained through a small axillary thoracotomy in the third intercostal space made posterior to the pectoralis major muscle and anterior to the latissimus dorsi muscle. ${ }^{10}$ The PDA was then ligated with a triple ligature technique. No tube thoracostomy was done and fluid in the chest was aspirated before chest closure. An extrapleural, intercostal catheter ${ }^{11}$ was inserted before chest closure for the administration of $0.25 \%$ bupivacaine every 4 to 6 hours in the postoperative period. After operation the patients were not admitted to an intensive care unit but were admitted to a standard ward after a short stay in the postanesthesia care unit. Discharge from the hospital was planned on the next morning after operation.

Standard techniques were used for transcatheter occlusion of the ductus arteriosus with the use of Gianturco coils. ${ }^{4}$ All transcatheter procedures were done with intravenous sedation and local anesthesia. Patients underwent aortography both before and after coil placement to document immediate occlusion and placement of the coil or coils.

Data analysis. Data were obtained for all patients from retrospective review of hospital records. All direct costs to the patient were included and were quantified according to actual charges to the patient. These included all hospital charges and physician fees for the procedure including follow-up visits in the first month after the procedure. Preprocedure diagnostic tests were not included in the total costs. All postprocedure echocardiograms were done free of charge as part of the study and were not included in the cost analysis. Indirect costs such as parental absence from work and psychologic and social costs of pain and thoracotomy were not quantified or included in the analysis. All patients were contacted through direct clinic visits to document any out-of-hospital complications.

Results are described as mean plus or minus the standard deviation. Comparisons of means were done with a Student's $t$ test and a $p$ value $<0.05$ was considered significant.

\section{Results}

Table I lists data for patient age, weight, procedure length, charges, and complications in both the transcatheter coil occlusion and surgical ligation groups. There were no early or late deaths in either group of patients. In two patients in the coil occlusion group the PDA appeared larger than $5 \mathrm{~mm}$ on angiography and coil occlusion was not attempted. These two patients subsequently underwent surgical ligation and are included in the surgical group, but 
only for the costs of the procedure related to operation. The total charges for these two patients to undergo catheterization and attempted coil occlusion followed by surgical ligation were $\$ 14,103$ and $\$ 13,929$, respectively. Patients in the coil occlusion group underwent fluoroscopy for an average of $16 \pm 10$ minutes during the procedure.

In the surgical group, complications occurred in four patients: one with a transient left recurrent laryngeal nerve injury, two with postoperative pneumothorax, and one with prolonged nausea and vomiting that necessitated hospitalization for more than 36 hours. Both patients with pneumothorax required only needle aspiration and hospitalization was not prolonged. One patient in the transcatheter coil occlusion group and one patient in the surgical group were admitted to the intensive care unit electively, early in the experience with both procedures. No patient in either group required blood transfusion. Late patency was found in two patients in the coil occlusion group and both patients had inaudible murmurs with patency only detectable by color-flow Doppler echocardiography at 1 month and 22 months, respectively. There have been no other complications in the coil occlusion group, including late pulmonary artery stenosis, coil embolization, or femoral artery occlusion.

\section{Discussion}

Since the first description by Gross and Hubbard ${ }^{1}$ in 1939, surgical ligation or division has remained the standard treatment for patients with PDA. ${ }^{2}$ Recently, less invasive techniques have gained wider acceptance and have included thoracoscopic clipping of the PDA, ${ }^{5}$ Rashkind occlusion device closure, ${ }^{3}$ and coil occlusion of the PDA with Gianturco coils. ${ }^{4}$ These newer treatment modalities have been perceived to cost less and be as effective as standard surgical techniques. ${ }^{6,12}$ Most of these studies have compared the newer modalities against standard thoracotomy and surgical ligation with relatively older patient care techniques. Use of critical pathway methods has had a favorable impact on length of stay and hospital costs when applied to children with congenital heart disease, including PDA. ${ }^{8}$ In addition, other less traumatic techniques such as muscle-sparing ${ }^{13}$ or axillary thoracotomy and the avoidance of tube thoracostomy ${ }^{10}$ have a favorable impact on care of the patient with PDA. We reasoned the combination of these critical pathway techniques with muscle-sparing axillary thoracotomy would be the most appropriate way to compare transcatheter coil occlusion with surgical ligation of a PDA.

Previous studies have shown conflicting results with regard to cost of surgical approaches that used thoracotomy as compared with transcatheter or thoracoscopic techniques. In 1993 Gray and associates $^{3}$ concluded that surgical ligation was less costly and more effective in closure of the PDA when compared with use of the Rashkind PDA occluder. In a smaller but similar study Human and associates ${ }^{14}$ demonstrated almost identical costs for surgical closure and use of the Rashkind PDA occluder device. In their study, the surgical ligation group had a hospital length of stay of 5.8 days, which undoubtedly contributed to costs in the surgical group. ${ }^{14} \mathrm{~A}$ recent study by Rothenberg and colleagues ${ }^{12}$ demonstrated thoracoscopic closure of the PDA to be more cost effective than a standard surgical approach, but with a length of stay in the surgical group of " 3 to 4 days." There is no doubt a more "modern" surgical cohort group with a length of stay of 24 to 48 hours, as in this study, would allow a more favorable comparison of surgical ligation or division with video-assisted thoracoscopic ductal closure. Other larger series of video-assisted thoracoscopic ligation of PDA have not directly addressed the question of costs. ${ }^{5,15}$ More recent reports of transcatheter coil occlusion techniques have demonstrated a lower cost for transcatheter coil occlusion as compared with surgical ligation, but have had a rather expensive comparison group for the surgical cohort ${ }^{6,16}$ as compared with the costs in the current study. Although length of stay was not described in the comparative studies by $\operatorname{Lohr}^{6}$ and Fedderly ${ }^{16}$ and their coworkers, hospital costs for surgical ligation, exclusive of professional fees, were nearly twice those in our study.

Costs for transcatheter coil occlusion may be reduced even more as experience is gained. Costs for surgical ligation were relatively low in our series and nearly identical to the low costs of transcatheter coil occlusion (Table I). This is likely a result of the relatively short length of stay (mean, 28 hours) in the surgical group, avoidance of the intensive care unit, and reduction of tests and medications to only essentials. It is also possible that the excellent pain control obtained with extrapleural intercostal nerve block assisted with better pulmonary mechanics and quicker recovery, thereby allowing earlier hospital discharge. ${ }^{11}$

In our study, we quantitated only inpatient and subsequent outpatient hospital charges and did not 
make an attempt to quantitate indirect or social costs. These indirect costs can be important to patients' families when considering the best option for a child with PDA. ${ }^{3,14}$ For instance, the loss of parent's income during absence from work and the psychologic and social costs of postthoracotomy pain and scarring were not quantitated. However, the surgical approach does not have potential disadvantages that are hidden in the transcatheter coil occlusion approach such as radiation exposure from fluoroscopy and the possibility of the need for a second procedure if coil occlusion cannot be done or is unsuccessful.

The efficacies of transcatheter coil occlusion, of use of the Rashkind PDA occluder device, and of operation have been documented in the literature. Closure of PDA with the Rashkind occluder device has been associated with a relatively high early patency rate by color Doppler echocardiography of $25 \%$ to $35 \%,{ }^{3}$ but with much more acceptable long-term residual patency rates as low as $4 \%$ in some series. ${ }^{17}$ Transcatheter coil occlusion seems to have slightly better results, but large multiinstitutional studies have also demonstrated early $(<1$ month) patency rates that approached $30 \%$, but that declined to $4 \%$ in patients followed up for more than 6 months. $^{7}$ Thoracoscopic closure or clipping of the PDA also is associated with residual patency that has been reported as high as $10 \%$ to $12 \%$ in some series. ${ }^{12,15}$ Surgical ligation has been reported to have a residual patency rate as high as $22 \%,{ }^{18}$ but this is likely dependent on the surgical technique used. The techniques used in the series from Sorensen, Kristensen, and Hansen ${ }^{18}$ included only single suture ligation or single clipping. We would caution against the use of a single ligature inasmuch as we and others have had residual patency with use of this method. ${ }^{2 \times 17,19} \mathrm{We}$ believe double or triple ligation and, certainly, division of the PDA are associated with a negligible residual patency rate as indicated by our results and those of others ${ }^{2,14}$ and likely remain the standard by which the efficacy of newer therapies should be measured.

The natural history and clinical implications of residual color-flow Doppler patency of a coil-treated or surgically treated PDA, in the absence of a clinically undetectable murmur, are unknown and would be difficult to determine. Almost all natural history data have been determined from patients who had clinically detectable murmurs and have been from before the era of color-flow Doppler echocardiography. ${ }^{20}$ Certainly endarteritis has been reported in a patient with an inaudible murmur, ${ }^{21}$ but the likelihood is that the "clinically silent" residual PDA is a relatively benign "techno-malady" that would require a relatively large amount of resource utilization with potential complications to effectively eliminate risk in all patients. ${ }^{22,23}$

Complications in our series were relatively few and generally not major. The major complication in the coil occlusion group was residual patency of the PDA. Although not strictly a complication of coil occlusion, the decision not to attempt placement of a coil because of PDA size represents an adverse outcome for a patient who enters the catheterization laboratory expecting to have closure of a PDA. This has been reported in $2.5 \%$ to $26 \%$ of patients undergoing attempted coil occlusion of a PDA. ${ }^{6,7}$ It is likely that with further experience better selection of patients by echocardiography will reduce to an acceptable level the number of patients with conditions found unsuitable for transcatheter coil closure. Because of our reluctance to attempt coil occlusion in patients with large or unfavorably shaped PDAs, we have had none of the complications seen by others such as left pulmonary artery stenosis, coil embolization, and femoral artery occlusion or injury. Complications in the surgical group have also been relatively minor. Our prevalence of recurrent laryngeal nerve injury of 5\% (Table I) is similar to that in larger series of surgical treatment of $\mathrm{PDA}^{24}$ and remains higher than the negligible or nonexistent prevalence in transcatheter techniques. It is possible that this method of axillary thoracotomy could have adverse late complications such as scoliosis or late thoracotomy pain, because long-term functional results with use of this technique are lacking. ${ }^{10,13,25}$ It would be expected, however, that the minimal dissection and muscle sparing used in the axillary technique would have fewer adverse effects on pain and scoliosis than the more traditional full lateral thoracotomy. Pneumothorax occurred in $10 \%$ of our patients, but this was a complication that was a result of the avoidance of tube thoracostomy and was easily treated without prolongation of hospitalization. Axillary thoracotomy without tube thoracostomy has been previously shown to be a safe technique for PDA ligation with a minimal occurrence of significant pneumothorax. $^{10}$

Surgical treatment of PDA remains the standard by which newer, less invasive techniques must be measured both in terms of cost and efficacy. Transaxillary, muscle-sparing thoracotomy without 
tube thoracostomy, triple ligation, and critical pathway methods allow safe and effective ligation of a PDA with early hospital discharge. This surgical method has a similar overall cost, higher efficacy rate, and applicability in all patients as compared with newer transcatheter coil occlusion techniques for closure of PDA. Despite these advantages of surgical ligation, coil occlusion is effective for the small PDA and is currently the procedure of choice in our institution for the smaller PDA because it does allow successful closure in the vast majority of patients without the need for overnight hospitalization or a scar. Only longer term follow-up, more experience, and prospective evaluation of transcatheter coil occlusion will determine whether this less invasive technique will become the standard technique for closure of PDA.

\section{REFERENCES}

1. Gross RE, Hubbard JP. Surgical ligation of a patent ductus arteriosus: report of first successful case. JAMA 1939;112: $729-31$.

2. Mavroudis C, Backer CL, Gevitz M. Forty-six years of patent ductus arteriosus division at Children's Memorial Hospital of Chicago: standards for comparison. Ann Surg 1994;220:40210.

3. Gray DT, Fyler DC, Walker AM, et al. Clinical outcomes and costs of transcatheter as compared with surgical closure of patent ductus arteriosus. N Engl J Med 1993;329:1517-23.

4. Moore JW, George L, Kirkpatrick SE, et al. Percutaneous closure of the small patent ductus arteriosus using occluding spring coils. J Am Coll Cardiol 1994;23:759-65.

5. Laborde F, Noirhomme P, Karam J, Batisse A, Bourel P, Saint Maurice O. A new video-assisted thoracoscopic surgical technique for interruption of patent ductus arteriosus in infants and children. J Thorac Cardiovasc Surg 1993;105:27880.

6. Lohr JL, Rochini AP, Hunter DW, Hardin JT, Bass JL. Cost effectiveness of coil embolization of patent ductus arteriosus (abstract). J Am Coll Cardiol 1995;25(suppl A):350A.

7. Lloyd TR, Beekman RH, Moore JW, et al. The PDA coil registry: 250 patient-years of follow-up (abstract). J Am Coll Cardiol 1996;27(suppl A):34A.

8. Turley K, Tyndall M, Roge C, et al. Critical pathway methodology: effectiveness in congenital heart surgery. Ann Thorac Surg 1994;58:57-65.

9. Galal O, Abbag F, Fadley F, Redington A, Szurman P, Oufi $\mathrm{S}$. Transcatheter closure of the patent arterial duct as a day-case procedure. Cardiol Young 1995;5:48-50.

10. Miles RH, DeLeon SY, Muraskas J, et al. Safety of patent ductus arteriosus closure in premature infants without tube thoracostomy. Ann Thorac Surg 1995;59:668-70.

11. Eng J, Sabanahan S. Site of action of continuous extrapleural intercostal nerve block. Ann Thorac Surg 1991;51:387-9.

12. Rothenberg SS, Chang JHT, Tocws WH, Washington RL. Thoracoscopic closure of patent ductus arteriosus: a less traumatic and more cost-effective technique. J Pediatr Surg 1995;30:1057-60.
13. Karwande SV, Rowles JR. Simplified muscle-sparing thoracotomy for patent ductus arteriosus ligation in neonates. Ann Thorac Surg 1992;54:164-5.

14. Human DG, McIntyre L, Gniewck A, Hanna B. Technology assessment of nonsurgical closure of patent ductus arteriosus: an evaluation of the clinical effectiveness and costs of a new medical device. Pediatrics 1995;96:703-6.

15. Burke RP, Wernovsky G, van der Velde M, Hansen D, Casteneda AR. Video-assisted thoracoscopic surgery for congenital heart disease. J Thorac Cardiovasc Surg 1995;109: 499-508.

16. Fedderly RT, Beekman RH, Mosca RS, Bove EL, Lloyd TR. Comparison of hospital charges for closure of patent ductus arteriosus by surgery and by transcatheter coil occlusion. Am J Cardiol 1996;77:776-9.

17. Magee AG, Stumper O, Burns JE, Godman MJ. Mediumterm followup of residual shunting and potential complications after transcather occlusion of the ductus arteriosus. $\mathrm{Br}$ Heart J 1994;71:63-9.

18. Sorensen KE, Kristensen BO, Hansen OK. Frequency of occurrence of residual ductal flow after surgical ligation by color-flow mapping. Am J Cardiol 1991;67:653-4.

19. Gross RE, Longino LA. The patent ductus arteriosus: observations from 412 surgically treated cases. Circulation 1951;3: 125-37.

20. Campbell M. Natural history of persistent ductus arteriosus. Br Heart J 1968;30:4-13.

21. Balzer DT, Spray TL, McMullin D, Cottingham W, Canter CE. Endarteritis associated with a clinically silent patent ductus arteriosus. Am Heart J 1993;125:1192-3.

22. Latson LA. Residual shunts after transcatheter closure of patent ductus arteriosus: a major concern or benign "technomalady"? Circulation 1991;84:2591-3.

23. Lloyd TR, Beekman RH. Clinically silent patent ductus arteriosus [Letter]. Am Heart J 1994;127:1664.

24. Fan LI, Campbell DN, Clarke DR, Washington RL, Fix EJ, White CW. Paralyzed left vocal cord associated with ligation of patent ductus arteriosus. J Thorac Cardiovasc Surg 1989; 98:611-3.

25. Massimiano P, Ponn RB, Toole AL. Transaxillary thoracotomy revisited. Ann Thorac Surg 1988;45:559-60.

\section{Discussion}

Dr. J. Terrance Davis (Columbus, Ohio). We had a similar interest in doing this type of study in Columbus, and as we looked at our cost accounting, we found an interesting bias against operation. That is, the operating room has traditionally been considered a profit center and, as such, replacement expenses for all of the equipment are rolled into the charge along with some sort of fudge factor. On the other hand, catheterization laboratory charges are done differently. The major capital equipment there has been funded by a capital budget, charges for which are not rolled into the usage fees. Significant personnel paid by other budget areas are also used in the catherization laboratory. Thus in a sense the hospital significantly subsidizes the catherization laboratory charges, whereas the opposite is true in the operating room. I wondered whether the charges in this study were just straight charges off of the hospital bill or whether there was cost accounting involved.

Dr. Hawkins. I took a rather simplistic approach to 
looking at the charges in this, and what I tried to analyze was the number that patients would get if they went home, took all of the bills, and added them up on a pocket computer. This is simply the actual bills that they received. I am not sure about the cost accounting in our operating room. Our operating room is charged by the minute. I am sure there are some capital budget items that are built into this charge. The cardiac catheterization lab, I think, is charged on a per procedure basis and not on a per minute basis. However, I cannot answer your question about exactly the cost accounting that was done.

Dr. Robert A. Guyton (Atlanta, Ga.). My understanding is that these were the first 20 coil occlusions done at the authors' institution. Do they really think it is fair to compare the first 20 with the authors' last $5 \%$ ?

Dr. Hawkins. That is a good question. You are taking the approach of the devil's advocate of surgical ligation, and the results probably are not the same. I think that our cardiologists have learned something in these first 20 patients. I think what they have learned to a certain extent is which patients in whom not to try coil occlusion. The other thing that I think they have learned is to not leave the catheterization lab with any aortographic evidence of residual patency. Despite the learning curve, I think in large multiinstitutional studies, which were just reported at the American College of Cardiology, there is going to be a residual patency rate with coil occlusion that is probably about in the $5 \%$ range in the long term no matter how this is done. My own bias is for operation. Yes, it is the cardiologists' first 20 patients, but to a certain extent it is also our first 20 patients, at least with this new technique. Surgical ligation has been done for about 50 years, so some may argue it is not fair to compare.

Dr. D. Craig Miller (Stanford, Calif.). But surgical ligation has not been done this way for 40 or 50 years or so, right?

Dr. Hawkins. No.

Dr. D. Glenn Pennington (Winston-Salem, N.C.). I think this study is important. Of course, the third alternative is thoracoscopic closure of the PDA, and I wonder where the authors think that fits into this schema.

Dr. Hawkins. We did not look at and we do not perform thoracoscopic closure of the PDA at our institution. I think the procedure is probably here to stay. I think one disadvantage that it has is that it requires high costs and high-technology material that is expensive. Personally, it is difficult for me to see that this short incision is that much different from four small incisions added up, but I am sure the thoracoscopic advocates would argue with me on that issue.

Dr. Richard A. Jonas (Boston, Mass.). We have moved in Boston to using video-assisted thoracoscopic ligation of the ductus as a routine. In comparison with catheterization laboratory capital expenditure, the equipment really is not all that expensive. In our own practice I believe it has been associated with a significant decrease in charge. Is that the next study to be done: comparison of videoassisted thoracoscopic ligation of the ductus and coil occlusion?

Dr. Hawkins. There has been one study of videoassisted thoracoscopic versus surgical ligation out of Denver by Rothenberg (Rothenberg SS, Chang JHT, Toews WH, Washington RL. J Pediatr Surg 1995;30:1057-60). His results, however, compared it with an older method of surgical ligation of the PDA with hospital stays that averaged almost 3 days, so $I$ do not think that is a fair comparison in 1996. I do agree that comparison of video-assisted thoracoscopic ligation with modern critical pathway regular surgical methods is the next step, and not only comparison of cost but also comparison of pain control and other variables on down the line.

Dr. Miller. I believe Dr. Jonas was interested in videoassisted thoracoscopic ligation versus coil occlusion.

Do you think that is a good idea?

Dr. Hawkins. Yes, I think it is the natural extension.

Dr. Randall B. Griepp (New York, N.Y.). Some of us have thought that one of the advantages of surgical closure is that it is actually division and closure in which there is a zero incidence of recanalization. Would the authors feel comfortable through this incision doing a division and closure, particularly with a large ductus arteriosus?

Dr. Hawkins. I would feel comfortable doing division with this technique. It is a small incision. But I do not totally feel comfortable doing division in every case. This is just a personal preference. I think triple ligation is a little bit easier to do without the risk of bleeding. 